NBER WORKING PAPER SERIES

\title{
IMPACT OF AUGMENTED PRENATAL CARE \\ ON BIRTH OUTCOMES OF MEDICAID \\ RECIPIENTS IN NEW YORK CITY
}

Theodore Joyce

Working Paper 6029
NATIONAL BUREAU OF ECONOMIC RESEARCH 1050 Massachusetts Avenue
Cambridge, MA 02138
May 1997

This work was supported by a grant from the Agency for Health Care Policy and Research (AHCPR) to the National Bureau of Economic Research (NBER) [Grant No.: R03 HS08424-01]. I have benefited greatly from discussions with Robert Kaestner. I owe thanks to Barbara Brustman, Lawrence Clark, and Georgie DiFerdinando from the New York State Department of Health, Steve Schwartz, Director of Vital Statistics, New York City Department of Health and from John Black, New York City Bureau of Medicaid Analysis for help with data and Ewa Wojas for research assistance. Finally, I am grateful to Michael Grossman, Andrew Racine and Howard Minkoff and to participants in the Boston University, Harvard and M.I.T. health economics seminar. As always, any errors are mine. This paper is part of NBER's research program in Health Economics. Any opinions expressed are those of the author and not those of the National Bureau of Economic Research.

(C) 1997 by Theodore Joyce. All rights reserved. Short sections of text, not to exceed two paragraphs, may be quoted without explicit permission provided that full credit, including $\mathbb{C}$ notice, is given to the source. 
Impact of Augmented Prenatal Care on Birth

Outcomes of Medicaid Recipients in New York City

Theodore Joyce

NBER Working Paper No. 6029

May 1997

JEL No. I18

Health Economics

\begin{abstract}
I examine whether New York State's Prenatal Care Assistance Program (PCAP) is associated with greater use of prenatal services and improved birth outcomes. PCAP is New York State's augmented prenatal care initiative that became a part of the Medicaid program after expansion in income eligibility thresholds in January, 1990. Data are from the linkage of Medicaid administrative files with New York City birth certificates (N=23,243). For women on cash assistance, I find PCAP is associated with a 20 percent increase in the likelihood of enrollment in WIC, an increase in mean birth weight of 35 grams and a 1.3 percentage point drop in the rate of low birth weight. Associations between PCAP and improved birth outcomes for women on medical assistance are similar, but appear contaminated by selection bias. Reductions in newborn costs associated with PCAP participation are modest, between $\$ 100-\$ 300$ dollars per recipient, and are insufficient to offset program expenditures.
\end{abstract}

Theodore Joyce

National Bureau of Economic Research

50 East 42nd Street

17th Floor

New York, NY 10017-5405

tjjbb@cunyvm.cuny.edu 


\section{Introduction}

Evaluations of the Medicaid changes in the late 1980's have been primarily concerned with the impact of eligibility expansions on enrollment, prenatal care utilization and birth outcomes (Piper, Mitchel, Ray and Griffin 1990; Piper, Mitchel and Ray 1994; Currie and Gruber 1996; Cole 1995; Kenney and Dubay 1995). Changes in Medicaid, however, were not limited to increases in income eligibility thresholds. Legislation also permitted states to offer enhanced reimbursement to qualified providers that provided comprehensive prenatal services to Medicaid recipients. By 1992, 37 states reimbursed qualified obstetric providers for augmented prenatal services ranging from case management to health education (Frost et al. 1993).

The question of whether augmented prenatal care programs are effective arises at a significant junction in health care policy for the poor. First, most studies that have examined the impact of the Medicaid eligibility expansions have demonstrated little improvement in birth outcomes. One possible explanation for these findings is that reduced financial barriers have little impact because poor pregnant women experience a myriad of problems that requires a more comprehensive approach to prenatal care (Guyer 1990). Although a majority of states have implemented comprehensive prenatal programs for pregnant women on Medicaid, participation may not have been sufficiently extensive to appreciably affect aggregate outcomes. Second, there is a rapid expansion toward Medicaid managed care. It is unclear whether state policy makers should require, and be willing to pay for, comprehensive prenatal services for poor women enrolled in managed care? Third, foreign-born women in New York City experienced the greatest increase in Medicaid enrollment following New York State's eligibility expansions in January, 1990. Legal and illegal immigrants were equally eligible for coverage. Welfare reform, however, may dramatically alter access to Medicaid and augmented care programs for illegal immigrants as well as legal immigrants who arrived after August, 1996. What effect benefit reduction might have on immigrants in states like California, New York, Texas and Florida is unknown. 
The experience in New York City should offer some evidence as to possible impacts of lost coverage for prenatai care to potentially large numbers of foreign-born women.

Three studies based on single-state analyses show that augmented prenatal care programs for Medicaid recipients improve birth outcomes (Buescher et al. 1991; Korenbrot et al. 1995; Reichman and Florio 1996). There is also evidence from studies that randomized women between comprehensive and routine prenatal care that birth outcomes improve with more intensive prenatal services (Olds et al. 1986; McLaughlin et al. 1992). The evidence, however, is far from robust. An analysis from Tennessee found no association between case management for pregnant Medicaid recipients and infant health (Piper et al. 1996). Moreover, potential selection bias is addressed in only one of the studies based on secondary data (Reichman and Florio 1996). Nor do the studies based on randomized designs provide the long-sought "gold standard" against which other prenatal evaluations should be measured. Olds et ai. (1986), for instance, report that comprehensive prenatal care is associated with an increase of 395 grams among teens but has no effect among older women. Not oniy are such gains implausibiy large but they are based on births to only 45 adolescents. The findings, therefore, are so selective and based on such smail samples as to call into question their relevance to large, state initiatives under Medicaid.

In this study I examine whether New York State's Prenatal Care Assistance Program (PCAP) is associated with greater use of prenatal services and improved birth outcomes. PCAP is New York State's augmented prenatal care initiative that became a part of the Medicaid program after expansion in income eligibility thresholds in January, 1990. Unlike most previous analyses of comprehensive prenatal care initiatives at the state level, I use several strategies in an attempt to minimize potential bias from unobserved differences between participants and non-participants of PCAP that are related to infant health. Specifically, I stratify the analysis by year and Medicaid category since women on cash assistance are primarily U.S. citizens whose eligibility was unaffected by the expansions. By contrast, women on medical assistance are predominantly foreign-born and potentially more heterogeneous than women on cash assistance given the doubling of income eligibility thresholds. I further stratify analyses 
by the timing of the first prenatal care visit so as to compare participants of PCAP who initiate prenatal care early with non-participants who also began care promptly. The rationale is that women who initiate prenatal early, regardless of participation in PCAP, share similar concerns for the health of the fetus that are difficult to measure with observable characteristics available from vital statistics. Finally, I use the rapid rise in PCAP enrollment prompted by the Medicaid eligibility expansion in January, 1990 to instrument for PCAP participation. Previous analyses have been limited to a single cross-section of women and have been unable to exploit the quasi-experimental nature of the Medicaid expansion.

I find that in cross-sectional regressions, Medicaid recipients served by PCAP providers have more prenatal care visits, are more likely to be enrolled in WIC and have infants of greater mean birth weight than Medicaid recipients who receive prenatal care from non-PCAP providers. The treatment effects, although statistically significant, are modest. When I instrument for PCAP participation, treatment effects are eliminated for the sub-category of Medicaid recipients on medical assistance, but persist for women on cash assistance, although statistically insignificant. Finally, when I compare changes in birth outcomes before and after the Medicaid eligibility expansions between obstetric providers that changed PCAP status to providers that never changed, I find no association between increases in PCAP participation and improved birth outcomes. I conclude that comprehensive prenatai care targeted at women on cash assistance, primarily AFDC, are potentially effective, but that a blanket expansion of such services to women with less apparent need is questionable.

\section{Description of PCAP}

The Prenatal Care Assistance Program is New York State's comprehensive prenatal care initiative authorized by Congress under the Consolidated Omnibus Budget Reconciliation Act of 1985 (COBRA 1985). In order to be designated a qualified PCAP provider facilities had to demonstrate the capability to offer a prescribed range of comprehensive prenatal services or have established subcontracts with other qualified providers. The general categories of comprehensive care include risk assessment, nutritional services, health education, as well as prenatal diagnostic and treatment services. 
Providers must also offer after hours access and emergency consultation (New York State Department of Health 1989a).

Prior to 1990, PCAP was a state funded grant program separate from Medicaid that reimbursed providers on a fee-for-service basis for prenatal and postpartum visits. PCAP did not cover inpatient hospital costs and physician or nurse midwife delivery fees were iow and only ailowable under specific circumstances. Reimbursement for prenatal care visits under PCAP, however, was substantially greater than payment under Medicaid. In 1988 Medicaid paid approximateiy $\$ 6 j$ dollars per obstetric outpatient visits in New York City municipai hospitais. PCAP, by contrast, paid $\$ 127$ for an initiai obstetric visit in New York City hospitals and \$76 per subsequent visit (New York State Department of Heaith 1989b). Eligibility for PCAP was also more generous than Medicaid prior to 1990 . Women with incomes less than 185 percent of the federai poverty level were eligible for PCAP whereas the Medicaid threshold was approximately 100 percent of poverty.

In January 1990, PCAP became part of the Medicaid program. From the provider's perspective subsumption of PCAP into Medicaid simplified biiling and more importantly, guaranteed providers a payor for delivery services. Reimbursement for prenatal and postpartum visits continued to exceed fees received by non-PCAP obstetric providers that served Medicaid recipients. ${ }^{1}$ More significantly, perhaps. PCAP providers had authority to declare a woman presumptively eilgible for Medicaid and were to serve as a client's advocate in the Medicaid application process. Clients no longer had to pursue medical assistance on their own. Nor was a client's immigration status relevant. With a minimum of organization, a PCAP provider after January 1990 couid indemnify against losses from serving, poor pregnant women.

One indication of how much Medicaid reforms faciiitated PCAP enrollment comes from the

\footnotetext{
${ }^{1}$ New York City hospitals and free-standing clinics received about $\$ 229$ in 1991 for an initial prenatal visit and $\$ 119$ dollars per visit thereafter. Reimbursement for ancillary services was included in these fees, which obviated more complex billing under the previous system. By design, the number of visits that could be billed was unlimited, which encouraged providers to err on the side of overutilization (New York State Department of Health 1989b).
} 
growth in deliveries covered by medical assistance and the changing characteristics of PCAP

participants. The bottom row of Tabie 1 shows the number of births to women by year, PCAP status and Medicaid eligibility. In the third quarter of 1989 there were 4,167 births $(2354+1813)$ to women on medical assistance in New York City . By 1991 that figure had risen to 6,588 (1190+5398), an increase of 58 percent. Even more striking is the increase in PCAP participation among women on medical assistance. Between 1989 and 1991, PCAP enrollment tripled among women on medical assistance.2 By the third quarter of 1991, 80 percent of PCAP participants on medical assistance were foreign-born [column (8)]. In short, summary data indicate that the Medicaid reforms aitered the modal characteristics of women served by PCAP providers from a U.S. native, who received cash assistance to an immigrant on medical assistance.

\section{Data}

Data used in this study are from the linkage of Medicaid administrative files with New York State birth certificates performed by the New York State Department of Social Services, Office of Health and Long Term Care. Ninety-three percent of all women on Medicaid who delivered a baby in New York State hospitals between July 1 and September 30, 1989 and July 1 through September 30 , 1991 were linked to birth certificates $(\mathrm{N}=43,503)$. In this study I use the subset of singleton births to New York City residents $(\mathrm{N}=23,249)$ as provided to me from the New York State Department of Social Services, Office of Health and Long Term Care ${ }^{3}$. The data distinguish women on Medicaid, but not cash assistance, from women whose Medicaid status is linked to their participation in Aid to Families with Dependent Children (AFDC), Supplemental Security Income ( SSI), and Home Relief (HR). Over 85 percent of women on cash assistance are in AFDC. The data also distinguish women on medical

2 This is somewhat of an overstatement since I do not know the number of women who were enrolled in PCAP but not on Medicaid in 1989. The number is probably stnall since only 12 pexcent of PCAP participants on medical assistance in 1991 would have been ineligible for Medicaid in 1989.

3 The original sample from New York State contained 23,249. I eliminated 1,084 observations due to missing data on both the number of prenatal care visits and the timing of the first visit. 
assistance who became eligible because of the expanded income threshold (100 to 185 percent of federal poverty level) from women whose income would have made them eligible for medical assistance prior to the expansion .

Designation as a PCAP enrollee varied between 1989 and 1991. In 1991, any woman eligible for Medicaid was automatically eligible for PCAP. Thus, if a Medicaid recipient receives an initial visit or revisit with PCAP provider she is considered a PCAP participant. The same criteria is used for 1989, however, receipt of care from a PCAP provider in 1989 did not guarantee that a woman on Medicaid obtained PCAP services, since providers could bill PCAP only if a woman had no other source of coverage. In 1989 New York State had not instituted presumptive eligibility for Medicaid, and thus, a woman's eligibility for Medicaid might not be determined until well after the initiation of prenatal care. This means a poor, uninsured woman could initiate prenatal care and receive PCAP services while her application for Medicaid was being processed. There is no information on how many Medicaid recipients received PCAP services in this manner. I make the assumption that Medicaid recipients who received care from a PCAP provider in 1989 received PCAP services. Misclassification of woman as PCAP participant who in fact did not receive PCAP services will bias results towards the null.

\section{Outcomes}

Except for Medicaid status, all other characteristics of mothers and infants are from the birth certificate. I examine three birth outcomes: birth weight, a continuous measure, and three dichotomous indicators, low birth weight (less than 2500 grams), very low birth weight (less than 1500 grams) and term low birth weight births (less than 2500 grams and greater than 37 weeks gestation). ${ }^{4}$ I examine two measures of prenatal care utilization. The first is the number of prenatal visits conditional on when

\footnotetext{
${ }^{4}$ Gestational age is the difference between date of birth and date of the mother's last menstrual period (LMP) as computed by the New York City Department of Health. If gestational age were missing or implausible I used the clinician's estimate of gestation. Otherwise I coded gestational age as missing $(n=318)$. There was substantial heaping of gestational age 40 weeks, especially in the clincian's estimate. For this reason I did not use gestational age as a separate outcome and limited the use to the dichotomous distinction between term and preterm births.
} 
prenatal care began. The second is participation in the Supplemental Program for Women, Infants and Children (WIC).

\section{Hypotheses and Methods}

The primary question of interest is the effect of PCAP participation on birth outcomes. I view the outcome equations as reduced form infant health production functions. I examine birth weight because it is a continuous, well-measured and frequently used indicator of infant health. I also use dichotomous measures of infant health because of their strong association with morbidity and mortality and their frequent use in the public health and epidemiological literature. In addition, I use several dichotomous measures of birth weight to distinguish plausible from implausible treatment effects associated with PCAP participation. Low birth weight, for example, can be broadly divided between infants born too soon and infants who grow too slow in utero. The general consensus in the clinical literature is that relatively little is known about the causes of preterm delivery (Collaborative Group on Preterm Birth 1993; Gibbs et al. 1992; Hatch and Merkatz 1995). Clinicians estimate that no more than 25 percent of preterm births are even theoretically preventable (Tucker et al. 1993). The epidemiology of fetal growth, however, offers more scope for intervention since smoking has such a well-documented link to fetal growth ( $\mathrm{Li}$ et al. 1993; Alexander and Korenbrot 1995). Inadequate maternal weight gain is also related to fetal growth retardation, although links between weight gain and nutrition are less consistent (Scholl et al. 1991). A reasonable interpretation of the clinical literature, therefore, is that one should be skeptical of associations between PCAP and very low birth weight since almost all infants less than 1500 grams are preterm. A more plausible association it likely to be found between PCAP participation and fetal growth given PCAP's emphasis on health education and nutritional counseling. As a proxy for fetal growth, therefore I will test whether PCAP is associated with birth weight and the rate of low birth weight among term births only (births 37 weeks gestation or greater).

I am also interested in whether women in PCAP receive more prenatal services than nonparticipants. By contract, PCAP providers are to provide nutritional services including provision of WIC 
resources to all eligible women. I would expect women in PCAP, therefore, to have a higher rate of WIC participation than women not in PCAP. Many poor women may have been enrolled in WIC prior to the present birth because of an older child. In this case, WIC could explain PCAP participation. To guard against reverse causality, I run regressions of WIC on PCAP for first births only. Another reason to assess the impact of WIC on PCAP is that should I find a positive association between PCAP and fetal growth, then a plausible mechanism would be differences in nutritional services as proxied by WIC (Rush et al. 1988; Devaney, Bilheimer and Schore 1992).

I also expect women in PCAP to have more prenatal visits, on average, than non-participants. A primary objective of PCAP is to insure that participants receive the necessary level of prenatal care. The New York State Department of Heaith requires that PCAP providers follow-up on missed appointments and make appropriate referrals. Moreover, New York state reimburses PCAP providers on a fee-forservice basis. As noted above, fees are relatively generous compared with payments received by nonPCAP obstetric providers who serve Medicaid recipients. The upshot is that PCAP's contractual stipulations as well as financial incentives may encourage visits.

\section{$\underline{\text { Selection bias }}$}

The main concern in the assessment of PCAP is selection bias. Do women who participate in PCAP, for example, have superior pre-pregnancy health, experience less stress, have fewer vaginal infections and are they less likely to engage in unhealthy behaviors than non-participants of similar income, schooling, race, age, marital status and reproductive history? If hard to measure factors that affect infant heaith aiso affect PCAP participation, then I may attribute gains to PCAP that in fact reflect these unobserved differences.

I take several approaches to selection bias. In each, I seek a set of controls that are likely to be similar in both observed and unobserved characteristics as women served by PCAP providers, the treatment group. I begin by stratifying all analyses by Medicaid category. I separate women on Medicaid through their enrollment in a cash assistance program (AFDC, SSI and Home Relief) from 
women who receive Medicaid coverage through the medical assistance program. Previous work has ignored this distinction. As noted above, there are large observed differences between women who receive cash assistance and those whose benefits are limited to medical assistance, the primary difference being nativity (see Table 1). The superior birth outcomes of foreign as compared to U.S. born women of similar socioeconomic status is a consistent empirical finding that is not well understood (Singh and Yu 1996). In addition, income guidelines for AFDC were not aitered between 1989 and 1991 whereas the Medicaid expansion increased the income eligibility threshold for medical assistance from approximately 100 to up to 185 percent of the federal poverty level. Newly eligible recipients may exacerbate heterogeneity among women on medical assistance.

I also stratify the analysis by year. In previous studies of enhanced prenatal care services, researchers have used a single cross-section of births to assess effectiveness. I have two cross-sections, separated by a major expansion in Medicaid, therefore PCAP, eligibility. The treatment protocol for PCAP participants, however, did not change between 1989 and 1991 and thus, I would not expect average treatment effects associated with PCAP to vary statistically between the two years. If treatment effects vary between 1989 and 1991, then there may have been a nonrandom response to the eligibility expansion. PCAP, for instance, may have attracted women at relatively low risk for adverse outcomes among the newly eligibles, which, all else constant, would increase average treatment effects relative to 1989. This is more likely to occur among women on medical as opposed to cash assistance given the rise in eligibility thresholds tor the former. In sum, I interpret a lack of temporal homogeneity of treatment effects as a warning of potential selection bias.

A third strategy to control for selection bias is to interact PCAP participation with the timing of the first prenatal care visit. One problem with a dichotomous measure of PCAP participation is that I am particularly interested in comparisons between PCAP participants who initiate care in the first four months of pregnancy with non-participants who also begin care early. I believe that the timing of the first prenatal care visit reflects concern for the pregnancy and a positive attitude toward primary care. 
More generally, comparisons based on the timing of first visit may distribute other hard to measure determinants of birth outcomes such as stress and unhealthy behaviors more equally between PCAP participants and nonparticipants. 5

\section{Instrumental Variables.}

I also attempt to correct for selection bias econometrically. I use growth in PCAP providers associated with the Medicaid eligibility expansion as an exogenous rise in availability that increased PCAP participation. ${ }^{6}$ I proxy changes in PCAP availability in three ways. First, I use the number of PCAP providers sites in 1988 and 1992 by health area. ${ }^{7}$ We have identified 66 PCAP sites in 1988 and 80 in 1992 , although this may be an undercount. ${ }^{8}$. As an additional instrument I use interactions between health district and year to capture general changes in PCAP availability. As a final strategy in the spirit of IV, I compare birth outcomes before and after the Medicaid expansion among three types of hospitals: those that were PCAP providers in 1989 and 1991; hospitals that were never PCAP providers in 1989 nor 1991; and hospitals that changed from non-PCAP to PCAP providers between 1989 and 1991. The purpose is to offer reduced form evidence of whether changes in a hospital's PCAP status increase PCAP participation and whether changes in PCAP status was associated with improvements in infant health.

For the IV procedure to be valid, there must be no direct effect of increases in availability on infant health. This would be violated, for example, if outreach by providers and the State Department of

\footnotetext{
5 Reichman and Florio (1996), for example, control for the timing of the first visit in regression of birth weight on receipt of comprehensive prenatal services. The specification assumes, however, that effects of augment prenatal care are the same regardless of when care begins. An interactive specification obviously relaxes this restriction. As I show below, the largest treatment effects associated with PCAP are for women who begin care after the seventh month of pregnancy, a dubious result highly suggestive of selection bias.

6 Reichman and Florio (1996) make a similar argument with respect to Healthstart in New Jersey. But theirs is a single cross section and thus, relies on a static measure of availability to identify participation.

7 New York City is divided into 352 health areas which aggregate up into 30 health districts.

8 The list of provider sites come from several sources. The New York State Department Social Services, Division of Health and Long Term Care provided me with a list of PCAP providers based on claims for PCAP services in 1989 and 1991. Each provider was histed only once regardless of how many outpatient sites it maintained. I obtained separate lists of PCAP sites from the New York State and New York City Departments of Health in 1988 and 1992. There were differences among the lists.
} 
Health induced favorable selection among pregnant women towards PCAP providers. It must be the case, therefore, that a woman's choice of obstetric provider is unaffected by the growth in PCAP sites. Put differently, women continue to access their local or regular obstetric provider regardless of a change in its PCAP status. This is not an unreasonable assumption. Women do not enroll in PCAP. Unlike AFDC , for example, women do not apply for PCAP at a centralized bureau. A woman on Medicaid automatically receives PCA.P services by virtue of her provider's status as a PCAP facility. Furthermore, by 1991, PCAP providers had authority to make decisions regarding presumptive eligibility for Medicaid. Thus, any uninsured woman who initiated care with a PCAP provider could be deemed presumptively eligible for Medicaid and enrolled in PCAP at the initial visit. The fact that PCAP grew so much between 1989 and 1991 among foreign-born women, most of whom would have been eligible prior to the expansion, suggests that increased availability of PCAP providers and streamlined enrollment procedures were important to the rise in participation.

Another potential difficulty with the IV strategy is the threat of omitted variable bias. As Moffitt (1996) points out, IV estimates identified by interactions between health district and year are equivalent to coefficients obtained from 30 -unit regression of health district changes in mean birth weight on health district changes in PCAP participation. If, for example, growth in PCAP providers occurred in heaith districts with diminishing drug use, then validity of the estimates is potentially compromised. Finally, I must demonstrate that year/health district interactions have appreciable explanatory power for PCAP participation, or I increase the likelihood of finite sample bias (Bound, Jaeger and Baker 1995). Given these considerations, I interpret IV estimates cautiously.

\section{Results}

Selected characteristics of women and infants by Medicaid status, PCAP participation and year are shown in Table 1. Women who receive cash as opposed to only medical assistance differ substantially along a host of demographic and behavioral measures. Women on cash assistance are more likely to be black non-Hispanic or Puerto Rican, less likely to be married, more likely to have been 
born in the U.S., have less schooling, and are more likely to have smoked or to have used cocaine during pregnancy than women who receive medical assistance only. Unsurprisingly, there are large differences in birth outcomes. Women who receive cash assistance have lower mean birth weight and higher rates of low birth weight [columns (1)-(4)] than women on medical assistance [columns (5)-(8)]. Differences in prenatal care are more muted. WIC participation and timing of the first prenatal visit are similar whereas mean visits differ; the latter can probably be explained by the greater proportion of women with no prenatal care among cash recipients.

When I examine differences by PCAP status within Medicaid categories over time, I observe that differences in birth outcomes between participants and non-participants grew substantially in two years. In 1989 , the rate of low birth weight was 10.0 percent among PCAP participants on cash assistance and 12.6 among non-participants [columns (1) and (2)]. Statistically significant differences also exist for mean birth weight. By 1991, these differences had increased. The rate of low birth weight rose from 12.6 to 15.1 percent between 1989 and 1991 among infants of cash recipients not in PCAP [columns (1) and (3)], and fell among infants of PCAP participants [columns (2) and (4)]. Shifts are so dramatic that by 1991 there is a 6.5 percentage point difference in the rate of low birth weight, and a 1.8 percentage point difference in the rate of very low birth weight between PCAP and non-PCAP participants on cash assistance in 1991 [columns (3) and (4)].

The same pattern exists for women on medical assistance [columns (5)-(8)]. As PCAP participation increased between 1989 and 1991, rates of low and very low birth weight increased among non-participants [columns (5) and (7)]. The worsening of outcomes among the shrinking pool of eligible non-participants appears explicable to some extent by changes in observable characteristics. The proportion of U.S. born women, the proportion of infants exposed to cocaine and tobacco, and the proportion of women with no prenatal care ail rose among non-participants of PCAP between 1989 and 1991. I turn; therefore, to the multivariate analysis in order to adjust for measured differences. 
Multivariate estimates of PCAP and birth outcomes

Average treatment effects of PCAP participation on three outcomes are displayed in Table 2:

birth weight measured in grams and dichotomous indicators of low birth weight and very low birth weight. $^{9}$ Each figure is from a separate regression estimated for each year and category of Medicaid. ${ }^{10}$ Estimates are adjusted for maternal age, race/ethnicity, mother's schooling, father's schooling, marital status, parity, infant's sex and census tract poverty rate. For births that occurred in 1991 among women on medical assistance I use an additional indicator of whether the woman qualified for Medicaid because her family income was between 100 and 185 percent of the federal poverty level. Standard errors are in parentheses. For each outcome I show, by row, estimates obtained from different samples. The first sample includes all births, the second excludes women with no recorded prenatal care, and the third sample includes term births only. ${ }^{11}$

Within Medicaid category and year, improvements in all birth outcomes associated with PCAP are greatest in samples that include women with no prenatal care. Moreover, the relative fall in treatment effects from exclusion of those with no prenatai care is roughly similar across Medicaid categories and year. For instance, among women on cash assistance in 1989 the adjusted mean difference in birth weight associated with PCAP is 69 grams [column (1)]. This falls to 47 grams when those with no care are excluded, a decline of 33 percent. Among women on cash assistance in 1991 , the average treatment effect associated with PCAP is 123 grams, but only 83 grams when I eliminate women with no care, again a fall of almost a third. The important point is that inclusion of women

9 The average treatment effect in the birth weight regression is simply the coefficient on the PCAP indicator. For the three binary outcomes estimated as probits, the average treatment effect is the mean of the difference in predicted probabilities for each woman assuming that she participated and then did not participate in PCAP. I used the delta method to obtain standard errors.

10 An F-test decisively rejected the null of homogeneity of coefficients between Medicaid categories $\left(F_{24, \propto}=4.23 ; p<.01\right)$. I also reject homogeneity by year for women on cash assistance $\left(F_{23, x}=1.72 ; p<.025\right)$, but not for women on medicai assistance $\left(\mathrm{F}_{24, \propto}=1.00\right)$.

11 Women enrolled in PCAP but with no recorded prenatal visits on the birth certificate are clearly misclassified. To be designated a PCAP enrollee, administrators in the New York State Department of Social Services would have to have received a claim for payment by a PCAP provider. Given the well-documented recording errors among birth certificates, the misclassification probably occurred among vital records (Piper et al. 1993). 
with no prenatal care has a substantial impact on average treatment effects and obscures understanding of PCAP. First, a woman on PCAP but with no prenatal care most likely represents misclassification (see footnote 14). Second, women with no prenatal care who do not participate in PCAP have such extreme rates of adverse outcomes and unhealthy behaviors that I view them as poor controls for women in PCA. ${ }^{12}$

Several patterns emerge when I focus on outcomes from samples that exclude women with no prenatal care. For instance, within Medicaid category, average treatment effects do not vary statistically by year, although some differences are large in magnitude. ${ }^{13}$ Thus, averaged across columns, I find that PCAP is associated with a statistically significant effect on birth weight of about 55 grams and a decrease in the rate of low birth weight of 2.0 percentage points. With one exception, I find no effects of PCAP on rates of very low birth weight.

To this point, therefore, findings are roughly equivalent to those reported in the literature. I view the lack of a consistent relationship between PCAP and very low birth weight favorably since I am skeptical that PCAP could have a meaningful impact on this subgroup of preterm infants. I now turn to results based on specifications in which I interact PCAP participation with the timing of the first prenatal visits. I also assess effects of PCAP on prenatal care visits and WIC participation.

\section{Effects of PCAP stratified by when care began}

I now examine differences by PCAP status and timing of the first visit in a multivariate context. Specifically, I run the following regressions:

$$
\mathrm{BW}=\mathbf{X} \beta+\delta_{1} \mathrm{~T} 1+\delta_{2}(\mathrm{PT} 1)+\delta_{3} \mathrm{~T} 2+\delta_{4}(\mathrm{PT} 2)+\delta_{5}(\mathrm{PT} 3)
$$

Let BW be the birth outcome and $\mathbf{X}$ the demographic and obstetrical determinants of birth used previously. Let $\mathrm{T} 1$ stand for women who begin prenatal care in the first four months of pregnancy and

\footnotetext{
12 For instance, in results not shown, the rate of low birth weight was 26.9 percent for infants to women on cash assistance but not in PCAP and who had no prenatal care in either 1989 or 1991 and 17.1 percent of the infants were exposed to cocaine $(n=561)$. For the similar women in PCAP, the rate of low birth weight was 17.1 percent and prevalence of cocaine, 9.5 percent $(n=473)$. In subsequent analyses, therefore, I eliminate all women with no prenatal care.
} 
who are not in PCAP; let PTI be women who also begin prenatal care in the first four months of pregnancy and who are enrolled in PCAP. Similarly, let T2 represent women who begin care in months five and six of pregnancy and let PT2 be those who begin care also in months five and six but who also participate in PCAP. Let PT3 be women who begin care in months seven through ten and who are enrolled in PCAP. The reference category is women who begin care late, months 7-10 and who do not participate in PCAP. Lastly, $\beta$ and $\delta_{i}$ are coefficients. I exclude women with no prenatal care.

I am not interested in individual coefficients per se since differences with respect to the reference category are uninformative. Instead I focus on mean differences and average treatment effects between women who initiate care around the same time during pregnancy. 14 Specifically I am interested in the magnitude and significance of $\delta_{2}-\delta_{1}, \delta_{4}-\delta_{3}$, and $\delta_{5}$, using the notation from equation (1). I present these differences for birth weight in Table 3 by Medicaid status, year and PCAP participation. Panel A shows results from the basic specification. Panel B adds measures of exposure to tobacco, cocaine, and other illicit drugs and Panel $\mathrm{C}$ is for term births only with exposure measures excluded. 15

The first coiumn of Panel A shows resuits for women on cash assistance in 1.989. I find that women in PCAP who begin prenatal care in the first four months of pregnancy have infants 54 grams heavier on average than women who aiso begin care eariy but who are not in PCAP. Looking across the top row of Panel A, 50 grams is about the average difference in adjusted mean birth weight. The exception is the comparison of women on cash assistance in 1991 in which the mean difference is 82

13 This is based on a z-score in which the standard error is the square root of the sum of the variances for each estimate. ${ }^{14}$ As before, average treatment effects for dichotomous outcomes are the percentage point differences in predicted probabilities obtained by averaging individual predictions across all women. Standard errors are obtained by the delta method.

is I appreciate that in a structurai production function such behavioral inputs are treated as endogenous. There is evidence that approximatey 25 percent of women stop or reduce smoking during pregnancy (Fingerhut, Kleinman and Kendrick 1990). There is less evidence of such precautions among women who abuse iilicit drugs. Data from the National Pregnancy and Health Survey shows that prevalence of cocaine use among the survey population is remarkably stable during the 12 months prior to delivery among black women, and women 25 to 29 years of age (National Institute on Drug Abuse 1996). There is also evidence that discharge abstracts and birth certificates identify illicit drug use among the sickest women (Joyce et al. 1995; Kaestner, Joyce and Wehbeh 1996). Our point is that for many addicted women, drug use precedes pregnancy, is maintained during pregnancy and is therefore, a 
grams. Comparisons between women who begin care in the fifth or sixth month of pregnancy are less consistent and measured imprecisely. Comparison between women who begin care late are remarkably consistent given small cell sizes and indicate about a 75 gram advantage to infants of mothers in PCAP. The latter result is large and suggests that PCAP has its greatest impact on women at greatest risk for an adverse birth outcome as measured by late initiation of prenatal care.

Figures in Panel B are from the same specification as in Panel A with the addition of three exposure measures. Reșuits from Panel A are essentially unchanged. Except for women on cash assistance in 1989, tobacco and illicit drug use are not confounders for PCAP participation. Estimates in Panel $\mathrm{C}$ show differences in birth weight by PCAP participation among term births only, a proxy for fetal growth. Specificaily, in 1989 women on cash assistance who initiated prenatal care in the first four months of pregnancy had infants at term that weighed 46 grams heavier, on average, than similar women who also began care early but who were not served by a PCAP provider. Average treatment effects for 1991 and for women on medicai assistance are less and statistically insignificant.

Estimated treatment effects associated with PCAP in Panel C are substantially smaller than those in Panel A and they imply that much of the increase in mean birth weight associated with PCAP comes from a reduction in preterm births. This is especially true of women who begin care after the sixth month of pregnancy. The 75-gram difference in mean birth weight in Panel A falls to approximately 22 grams in Panel $\mathrm{C}$ when we exclude preterm births. As argued above, the clinical literature offers little evidence that broadly applied interventions in the third trimester of pregnancy such as PCAP could affect the rate of preterm birth appreciably. A less sanguine interpretation, therefore, is that the relatively large treatment effects associated with PCAP among women who begin care late (Panel $\mathrm{A}$, third row) reflect unobserved heterogeneity between women who obtain PCAP services and those who do not.

In Table 4 I repeat the analysis from Table 3 but with the rate of low birth weight, the rate of term low birth weight and rate of very low birth weight as outcomes. Overall, results confirm general 
conclusions drawn from the analysis of birth weight. There is no consistent association between PCAP participation and very low birth weight among women who initiate care in the first four months of pregnancy (Panel C). I do show differences of approximately 2.8 percentage points in the rate of low birth weight among women who begin care early (Table 4, Panel A, row 1), but these estimates are reduced by about half when I exclude preterm births (Table 4, Panel B, row 1). As with birth weight, the most dramatic change in average treatment effects from excluding pretem births occurs among women who initiate prenatal care in the third trimester [Panel A, row 3 versus Panel B, row 3].

\section{Effects of PCAP on prenatal visits and WIC participation}

Table 5 displays differences in the average probability of WIC participation and prenatal care visits associated with PCAP. In Panel A, I show that women in PCAP. as compared to non-participants, are between 9 and 14 percentage points more likely to enroil in WIC. In relative terms this represents an increase of about 20 percent. In three out of four samples, differences in WIC participation by PCAP status fall modestly when I restrict the analysis to primiparas.

In Paneis $\mathrm{B}$, I show adjusted mean differences in prenatal care visits associated with PCAP. I restrict the comparison to term births in order to limit confounding with gestational age. Women in PCAP who initiate care early obtain less than half a visit more than women not served by a PCAP provider. Differences for women who begin care late are large, have the wrong sign and are difficult to expiain.

In summary, the positive association between PCAP and WIC is consistent with the finding of a modest increase in birth weight of term births, the proxy for fetal growth. The lack of difference in prenatal visits among women who began care early suggests that participants and non-participants of PCAP were equally compliant and that differences in birth outcomes cannot be attributed to less physician contact among non-participants and are consistent with the interpretation that women in PCAP receive more intensive care.

may be related to PCAP participation, it is a potentially useful control for heterogeneity. 
Instrumental Variables

To this point I have treated PCAP participation as exogenous. I have tried to limit unobserved heterogeneity between treatment and control groups by stratifying analyses by year and Medicaid category and interacting PCAP participation with timing of the first prenatal visit. In this section I present results based on instrumental variables. I pool data by year but not Medicaid category in order to exploit growth in PCAP availability as a result of Medicaid reforms in January 1990. I instrument a dichotomous indicator of PCAP participation on a set of health districts/year interactions and the number of PCAP provider sites by health area. 16 In particular, I estimate the following two equations:

$$
\begin{gathered}
\mathrm{PCAP}=\mathbf{X} \delta_{1}+(\mathbf{H D}) \delta_{2}+(\mathbf{H D} \mathbf{x} \mathbf{Y R}) \delta_{3}+\delta_{1} \text { PROVIDER }+\mathrm{u} \\
\mathrm{BW}=\mathbf{X} \beta_{1}+(\mathbf{H D}) \beta_{2}+\alpha_{1} \mathrm{PCAP}+\mathrm{v}
\end{gathered}
$$

Let $\mathrm{PCAP}$ be a dichotomous indicator of participation and $\mathrm{BW}$ represent a birth outcome. Let PROVIDER be the number of PCAP sites in a woman's health area of residence; let $\mathbf{H D}$ be the matrix of dummy indicators for 29 of the 30 health districts and $\mathbf{H D} \times$ Yr a matrix of be interactions between health district and year. I focus on two outcomes, birth weight and low birth weight. I use two-stage least squares when birth weight is the outcome and Murphy and Topel's (1985) two-estimator for low birth weight. For the latter, I estimate separate probits for equations (2) and (3), use the predicted probability of PCAP participation from equation (2) as a regressor in equation (3), and then adjust the standard errors in equation (3) to allow for cross-equation residual correlation. Single equation and IV estimates of $\alpha_{\mathrm{l}}$ are displayed in Table 6. All first-stage results are presented in Table Al of the Appendix.

Results based on instrumental variable (IV) estimates suggest that PCAP has no statistically significanteffect on birth weight or rates of low birth weight. Among women on cash assistance,

16 New York City subdivides health districts into health areas. There are 30 health districts and 352 health areas. 
however, IV estimates exceed those obtained by single equation methods and asymptotic t-ratios are greater than one. Based on a Wu-Hausman test I cannot reject the hypothesis that IV and OLS are different, nor that the over identification restrictions are inappropriate. Further, F-tests on the set of excluded instruments indicates that finite sample bias should not be a problem (Bound, Jaeger and Baker 1995).

Instrumental variable estimates for women on medical assistance, in contrast, indicate no association between PCAP and birth weight. In the birth weight regression the IV coefficient on PCAP has the wrong sign and is statistically insignificant. A Wu-Hausman test rejects homogeneity between IV and OLS estimates at the .05 level. A test of over identification tests supports the validity of the instruments and there is little evidence of finite sample bias from inadequate instruments. The IV estimates for women on medical assistance suggest that the positive associations between PCAP and infant health obtained from single-equation methods are contaminated by favorable selection.

As a final exercise, I compare the outcome of three groups of deliveries before and after the expansion in Medicaid eligibility in January 1990. I assume that many poor women who deliver at a hospital received prenatal services at the facility's outpatient or sateilite clinics. ${ }^{17}$ The question I ask is whether changes in a facility's status as a PCAP provider, is associated with changes in PCAP participation and birth outcomes. I view this as a reduced form or intention to treat analysis. The control groups consist of women who delivered at a hospitai that was either always a PCAP provider or never a PCAP provider between 1989 and 1991. The third, or treatment group, includes women who delivered at a hospital that changed from a non-PCAP provider in 1989 to a PCAP provider by 1991.

Table 7 displays key characteristics by hospital type, Medicaid category, and year. Take women on cash assistance. I show that in hospitals that were always PCAP providers the percentage of births to

\footnotetext{
${ }^{17}$ For reasons of confidentiality, I was not given information as to where a women received her prenatal care. Birth certificates, however, indicate the hospital of delivery. Thus, I knew whether a women received PCAP services and whether the hospital she delivered at was PCAP provider. From the data in Table 7, it is clear that a woman could have received prenatal services from a PCAP provider but delivered at a non-PCAP hospital. From the perspective
} 
women in PCAP is impressively stable: 80.5 percent in 1989 and 84.2 percent in 1991 . In contrast, the percentage of births to women in PCAP rises dramatically from 37.4 to 86.5 percent in hospitals that changed PCAP status between 1989 and 1991. Despite the large increase in PCAP participation there is no change in mean birth weight or the rate of low birth weight between 1989 and 1991 in either the treatment or control hospitals. There is, however, a large rise in WIC participation ( 55.5 to 65.1 percent) and prenatal visits ( 8.4 to 9.3 ) among women in the treatment group and little change among controls.

Results are essentially the same for women on medical assistance (lower panel, Table 7). The rise in PCAP participation in hospitals that were always PCAP providers is explained by the large increase in Medicaid enrollment after the January 1990 expansion. As expected, there is no change in the percentage of births to women in PCAP among hospitals that did not participate in the program. Rates of low birth weight fall aimost a percentage point between 1989 and 1991 for infants delivered in hospitais that became PCAP providers. They fell by the same amount in hospitals that didn't change and they fell even more in hospitais that were never PCAP providers. Not only are the differences not significant, but a simple difference-in-difference estimator would show no change associated with changes in PCAP provider status. In resuits not shown, adjustment for demographic and socio-economic characteristics of mothers had no effect on these inferences.

Reduction in newborn costs associated with PCAP

I conclude the analysis of PCAP with an estimate of reductions in newborn delivery costs associated with participation in PCAP. I want to emphasize that reduction in newborn delivery costs is a limited view of benefits and represents only a component of a more complete cost-effectiveness or cost-benefit analysis. ${ }^{18}$ To convert improvements in birth outcomes to reductions in newborn costs, I

of an "experiment," as long as referral patterns for deliveries from free-standing clinics did not appreciably change with the Medicaid expansion, comparisons between treatment and control hospitais should be useful.

18 I limit savings to newborn costs because I have data from another recently completed project in which we linked birth certificates to discharge abstracts for all deliveries in a New York City municipal hospital in 1991. I do not estimate lives saved because I do not assess infant mortality (See Currie and Gruber 1996). For the same reason I do not incorporate possible savings due to long term costs of low birth weight (See Lewit et al. 1995). 
use discharge abstracts linked to birth certificates of newborns whose mothers were on Medicaid and who delivered in a New York City pubiic hospital in $1991(\mathrm{n}=22,123) .19$ I regress the natural logarithm of newborn costs on birth weight and birth weight squared adjusted for the same set of demographic and socio-economic variables as in the birth outcome regressions. In another newborn cost regression I use a dichotomous indicator of low birth weight instead of a quadratic specification of birth weight. Coefficients from the newborn cost regressions are presented in Tables A3 and A4 of the Appendix.

Savings in 1991 dollars associated with decreases in birth weight and rates of low birth weight are displayed in Table 8. I assume that PCAP improves birth outcomes of ail participants equaliy and evaluate savings from two points. The first point is at the geometric mean of ail discharges $(\$ 2,165)$; the second is at the predicted cost of an infant that weighs 2,500 grams $(\$ 3,696)$. Based on the analysis of birth outcomes, I evaluate savings for three changes in birth weight and rates of low birth weight that vary from conservative to more optimistic. Thus, if PCAP improves birth weight on average by 30 grams, I estimate a reduction in newborn costs of $\$ 189$ per PCAP participant. 20 If I assume that the 30 gram increase raises an infant's weight from 2500 to 2530 grams, then savings rise to $\$ 322$ dollars. The lower haif of Table 8 shows results from a similar exercise with changes in the rate of low birth weignt aiso evaluated at two cost points. Finally, if I assume that PCAP has no effect on birth weight among women on medical assistance, then savings per participant are reduced by 47 percent, which is the proportion of PCAP participants on medical assistance in 1989 and 1991.

What are the incremental costs of PCAP? The preferred specification compares effects of PCAP for women who begin care in the first four months of pregnancy. The mean number of prenatal care visits for women who begin care early is approximately 10 . PCAP paid $\$ 229$ for an initial visit in a

19 Details as to the data can be found in Joyce, Racine and Grossman (1996).

20 The $\$ 189$ dollars in savings was obtained as follows: $\left[e^{\ln (2165)}\right.$. $\left.e^{\ln (2165)+\beta(30)+\alpha(900)}\right]$ where $\beta$ is the coefficient on the linear birth weight term and $\alpha$ is the regression coefficient squared birth weight term (see Appendix Table 2). 
public hospital outpatient clinic in 1991 and $\$ 119$ for each prenatal visit thereafter. 21 Outpatient fees under regular Medicaid were approximately $\$ 65$ dollars in 1991 for public hospitals in New York City. 22 Based on these figures, PCAP expends $\$ 651$ more than what would be paid under regular Medicaid for prenatal care initiated in the first four months of pregnancy. This is actually an overestimate of the difference since PCAP's fees include ancillary services and regular Medicaid fees do not. Let us allow $\$ 151$ dollars for ancillary services and assume that $\$ 500$ dollars per pregnancy is a reasonable estimate of the reimbursement difference between PCAP and regular Medicaid. According to figures in Table 8, reductions in the rate of low birth weight of 3 percentage points do not generate sufficient savings to recover prenatal costs under the assumption that PCAP affects all participants; PCAP must realize gains in birth weight of 50 or more grams for infants that weigh 2500 grams in order to recoup prenatal outlays. If I assume that PCAP has no effect on the birth outcomes of women on medical assistance, then even increases of 70 grams in birth weight or reductions in low birth weight of three percentage points among women on cash assistance would not generate sufficient reduction in newborn costs to offset increased fees to providers for all PCAP participants.

\section{Discussion}

In this study I test whether participation in New York State's Prenatal Care Assistance Program, PCAP, is associated with healthier infants. Based on adjusted means, I report a consistent and positive association between participation in PCAP and improved infant health. Specifically, I find women in PCAP have infants that weigh approximately 50 grams more and have rates of low birth weight 2.5 percentage points less than infants not enrolled. These results are similar to those reported by Reichman and Florio (1996) and Buescher et al. (1991). If, however, I eliminate preterm infants, gains associated

21 From the Appendix of the New York State Department of Health Prenatal Care Assistance Program Comprehensive Provider Agreement as provided by Nancy Cuddihy, then Director of the Perinatal Health Unit.

22 Personal communications with Joanne Marks, Finance Department Bronx Municipal Hospital and Medical Center. 
with PCAP participation fall to about 35 grams in mean birth weight and 1.3 percentage points in rates of low birth weight.

Results obtained from IV methods offer less support for an association between receipt of PCAP services and improved infant health. When I use health district /year interactions as instruments, estimates for women on cash assistance exceed those by single-equation methods, but are statistically insignificant. If, however, I compare birth outcomes between PCAP and non-PCAP hospitals between 1989 and 1991, I show no improvement associated with large increases in PCAP participation. The IV estimates for women on medical assistance as well as comparisons across hospital types indicate that PCAP has no effect on birth outcomes.

My conclusions, therefore, are more reserved than those reached by other researchers. For readers not persuaded by IV estimates, the most credible evidence of a positive association between PCAP participation improved birth outcomes occurs among term births for women on cash assistance. Support for this finding comes from the clinical relationship between increased fetal growth and reductions in smoking, and a less consistent but potential relationship between maternal weight gain during pregnancy and fetal growth. PCAP providers are under contractual obligation to promote health education and to offer nutritional counseling, both of which have the potential to affect smoking and weight gain. The finding that women in PCAP, even primiparas, are more likely to enroil in WIC is at least consistent with estimated improvements in the birth weight of term infants. It is also noteworthy that improvements in fetal growth are from a comparison of women all of whom began care in the first four months of pregnancy. Early prenatal care, a decision that originates with the patient, may be an important means to control for unobserved heterogeneity. In addition, there are small differences in adjusted mean prenatal visits among women who begin care early. Women in both treatment and control groups appear equally compliant and both see physicians with similar frequency. For these reasons, I view increases in mean birth weight of 35 grams or a 1.3 percentage point drop in rates of low birth 
weight as plausible estimates. These gains, however, are less than improvements attributed to comprehensive prenatal services reported elsewhere (Buescher at al. 1991; Reichman and Florio 1996).

Evidence of selection bias among PCAP participants is inferred by comparing results based on IV methods, which show no statistically significant effect PCAP on birth outcomes, to the estimated gains obtained by single equation methods. The IV estimates suggest that infants of women "moved" by the Medicaid expansion were unaffected by participation in PCAP (Angrist, Imbens and Rubin 1996). The validity of the IV estimates relies on whether the Medicaid expansion stimulated an exogenous increase in PCAP participation by both clients and providers. In this regard I find the simple comparison by hospitals in Table 7 compelling. First, there is no evidence to suggest large switching by women from non-PCAP to PCAP hospitals. Nor is their evidence that the quality of PCAP providers was greater in one group or another based on proportion of municipal hospitals (see Table A2 in the Appendix). The lack of any improvement in birth outcomes in the hospital that changed from PCAP to non-PCAP providers, despite the huge increase in PCAP participation, is consistent with the IV estimates and undermines results obtained by single equation methods.

The most important insight for future assessments of comprehensive prenatal services associated with the Medicaid expansions is the need to move beyond simple adjusteci means or odd ratios based on binary indicators of participation. Researchers should exploit variations in time, eligibility groups and geographic boundaries in an effort to create more plausible control groups or to generate instruments. Finally, health poiicy analysts should be able to defend the biological or epidemiological plausibility of reported associations. The general lesson emerging from analyses of the Medicaid expansions of the late 1980 's is that we may have overstated the effectiveness of prenatal care to improve infant health for many of the reasons just enumerated. Analyses of comprehensive prenatal services should avoid these mistakes so that more effective policies can be designed and implemented. 


\section{Acknowledgments}

This work was support by a grant from the Agency for Health Care Policy and Research (AHCPR) to the National Bureau of Economic Research (NBER) [Grant No. : R03 HS08424-01]. I have benefited greatly from discussions with Robert Kaestner. I owe thanks to Barbara Brustman, Lawrence Clark, and Georgie DiFerdinando from the New York State Department of Health, Steve Schwartz, Director of Vital Statistics, New York City Department of Health and from John Black, New York City Bureau of Medicaid Analysis for help with data and Ewa Wojas for research assistance. Finally, I am grateful to Michael Grossman, Andrew Racine and Howard Minkoff and to participants in the Boston University, Harvard and M.I.T. health economics seminar. As always, any errors are mine. 


\section{References}

Alexander, G. and C. Korenbrot, "The Role of Prenatal Care in Preventing Low Birth Weight." The Future of Children 5:103-120.1995.

Angrist, J., Imbens, G., and D. Rubin. "Identification of Causal Effects Using Instrumental Variables." Journal of the American Statistical Association 91:444-455. 1996.

Bound, J., Jaeger, D., and R. Baker, "Problems with Instrumental Variables Estimation when the Correlation Between the Instruments and the Endogenous Explanatory Variable Is Weak." Journal of the American Statistical Associaton 90:443-450. 1995.

Buescher, P., Roth, M., Williams, D., and C.Goforth, An Evaluation of the Impact of Maternity Care Coordination on Medicaid Birth Outcomes in North Carolina. American Journal of Public Health 81:1625-1629. 1991.

Cole, N. "Increasing Access to Health Care: The Effects of Medicaid Expansions for Pregnant Women. Report prepared by ABT Associates Inc. for Health Care Financing Administration, Contract No. 500-89-0063. 1995

Collaborative Group on Preterm Birth Prevention. "Multicenter Randomized, Controlled Trial of a Preterm Birth Prevention Program.” American Journal of Obstetrics and Gynecology 169:352366. 1993.

Currie J, and J. Gruber Saving Babies: The Efficacy and Cost of Recent Expansions of Medicaid Eligibility for Pregnant Women. Journal of Political Economv 104:1263-1296. 1996.

Devaney, B., Bilheimer, L., and J. Schore, "Medicaid Costs and Birth Outcomes: The Effects of Prenatal WIC Participation and the Use of Prenatai Care." Journal of Policy Analysis and Management 11:573-592. 1992.

Fingerhut, L. Kleinman, J. and J. Kendrick, "Smoking Before, During, and After Pregnancy." American Jourral of Public Health 80:541-544. 1990.

Frost, J., et al. State Implementation of the Medicaid Eligibility Expansions for Pregnant 
Women. New York:Alan Guttmacher Institute, 1993.

Gibbs, R.S., et al. "A Review of Premature Birth and Subclinical Infection." American Journal of Obstetrics and Gynecology 166:1515-1528. 1992

Guyer, B. "Medicaid and Prenatai Care." Journal of the American Medical Association 264:2264-2265. 1990.

Hack, M., and I. Merkatz. "Preterm Delivery and Low Birth Weight - A Dire Legacy." The New England Journal of Medicine 333:1772-1773. 1995.

Joyce, T. and A. Racine, An Analysis of Infant Mortality in New York City: 1988-89 and 1992-93. Final Report to the Metropolitan Health and Research Association of New York City. February, 1996.

Joyce, T., Racine, A. and M. Grossman, Neonatal Costs of Maternal Substance Abuse. Final Report of Grant No. 5 r01 DA07557 from the National Institute on Drug Abuse to the National Bureau of Economic Research. October, 1996.

Joyce, T. Racine, A. McCalla, S. and H. Wehbeh, "The Impact of Prenatal Exposure to Cocaine on Newborn Costs and Length of Stay." Health Services Research 302:341-358. 1995.

Kaestner, R., Joyce, T. and H. Wehbeh, "The Effect of Maternal Drug Use on Birth Weight: Measurement Error in Binary Variables." Economic Inquiry. 34:617-629. 1996.

Kenney, G. and L. Dubay, "A National Study of the Impacts of Medicaid Expansions Pregnant Women." Manuscript, The Urban Institute, 1995.

Korenbrot. C. et al. "Evaluation of California's Statewide Implementation of Enhanced Perinatal Services as Medicaid Benefits." Public Health Reports 110:125-134. 1995.

Li, C.Q., et al. "The Impact on Infant Birth Weight and Gestational Age of Cotinine-Validated Smoking Reduction During Pregnancy." Journal of the American Medical Association 269:1519-1524. 1993.

Lewit, G. et al. "The Direct Cost of Low Birth Weight." The Future of Children 5:35-56. 1995 
McLaughlin, FJ. et al . "Randomized Trial of Comprehensive Prenatal Care for Low-Income Women: Effect on Birth Weight. Pediatrics 89:128-132. 1992.

Moffitt, R. "Selection Bias Adjustment in Treatment-Effect Models as a Method of Aggregation. Proceedings of the American Statistical Association, 234-238. 1995.

Murphy, K. and R. Topel. "Estimation and Inference in Two-Step Econometric Models." Journal of Business and Economic Statistics 3:370-379. 1985

National Center for Health Statisitics. Health. United States. 1995. Hyattsville, MD: Public Health Service. 1996.

National Institute on Drug Abuse. National Pregnancy and Health Survey. Rockville, Maryland:National Institute on Drug Abuse, 1996.

New York State Department of Health. Department of Health Memorandum. Health Care Facilities Series: H-60, D \& TC-40, Series 89-91. November 11, 1989a.

New York State Department of Health. Prenatal Care Assistance Programs: 1988 Annual Report. Albany: New York State Department of Health, $1989 \mathrm{~b}$.

New York State Department of Health. Prenatal Care Assistance Programs: 1990 Annual Report. Albany: New York State Department of Health, 1990.

New York State Department of Health. "1991 Prenatal Care Assistance Program Impact Analysis." Mimeo. 1993.

New York State Department of Health. "Prenatal Care Assistance Program 1991-1992 Progress Report." Mimeo. 1995.

Olds, D.L., Henderson, C.R, Tatelbaum, R. and R. Chamberlin, "Improving the Delivery of Prenatal Care and Outcomes of Pregnancy: A Randomized Trial of Nurse Home Visitation." Pediatrics $77: 16-28.1986$.

Paneth, N. "The Problem of Low Birth Weight." The Future of Children 5:19-34. 1995.

Piper et al. "Validation of 1989 Tennessee Birth Certificates using Maternal and Newborn Hospital 
Records." American Joumal of Epidemiology 137:758-768. 1993.

Piper, J., Ray, W.A., Griffen, M.R. "Effects of Medicaid eligibility expansion on prenatal care and pregnancy outcome in Tennessee." JAMA 264:2219-2223. 1990.

Piper J.M., Mitchel E.F., and W.A. Ray, Expanded Medicaid Coverage for Pregnant Women to 100 Percent of the Federal Poverty Line. American Journal of Preventive Medicine 1994;10:97-102.

Piper J.M., Mitchel E.F., and W.A. Ray, Evaluation of a Program for Prenatal Care Case Management. Family Planning Perspectives 1996;28:65-68.

Piper, J.M. et al. "Validation of 1989 Tennessee Birth Certificates Using Maternal and Newbom Hospital Records." American Journal of Epidemiology 137:758-768. 1993.

Reichman, N. and M. Florio, "The Effects of Enriched Prenatal Care Services on Medicaid Birth Outcomes in New Jersey." Joumal of Health Economics 15:455-476. 1996.

Rush, D. et al. "National WIC Evaluation: Evaluation of the Special Supplemental Food Program for Women, Infants, and Children V. Longitudinal Study of Pregnant Women." American Journal of Clinical Nutrition 48(Supplement): 439-83. 1988.

Scholl, T. et al. "Maternal Weight Gain, Diet and Infant Birth Weight: Correlations during Adolescent Pregnancy." Joumal of Clinical Epidemiology 44:423-428. 1991.

Singh, G.K, and S.M. Yu, "Adverse Pregnancy Outcomes: Differences beteween US- and Foreign-Bom Women in Major US Racial and Ethnic Groups." American Journal of Public Health 86:837-43. 1996.

Tucker, J.M. et al. 1991. "Etiologies of Preterm Birth in an Indigent Population: Is Prevention a Logical Expectation?" Obstetrics and Gynecology 77:343-347.

U.S.Bureau of the Census. Statistical Abstract of the United States: 1995 (115 th $^{\text {edition}) ~ W a s h i n g t o n, ~}$ D.C., 1995. 
Table 1

Mean Characteristics of Mothers and Infants by Category of Medicaid, Year, and Enrollment in the Prenatal Care Assistance Program (PCAP) ${ }^{\text {a }}$

Cash Assistance

\begin{tabular}{c}
\multicolumn{2}{c}{19891991} \\
Non-PCAP
\end{tabular}

\section{Birth Outcomes}

Birth weight (g)rams

Low birth weight $\%$

Very low birth weight $\%$

Preterm births $\%^{+}$

\section{Prenatal care}

No. of visits ${ }^{+}$

Month care began ${ }^{+}$

No care ${ }^{+}$

WIC

\section{Demographic (\%)}

Whites/other non-Hisp

Black non-Hispanics

Puerto Rican

Dominican

Other Hispanic

Born in US

Unmarried

Mother's age $<20$

Mother worked during

pregnancy

\section{Behavioral (\%)}

Cocaine

$\geq 1 / 2$ pk cigarettes/day
(1)

$\begin{array}{rc}3116 & 3183^{* *} \\ 12.6 & 10.0^{* *} \\ 2.1 & 1.4 \\ 16.4 & 13.2^{* *}\end{array}$

7.3

3.4

12.0

36.3

10.6

44.7

26.1

11.9

5.0

68.6

77.2

16.9

8.1
(2)

(3)

3074
15.1
2.8
19.1

$7.8^{* *}$

$3.8^{* *}$

$6.4^{* * *}$

$46.6^{* *}$
6.8

3.2

17.1

37.3

\section{4}

50.0

21.4

12.0

4.5

70.7

79.3

18.9

6.6

$\begin{array}{rr}6.3 & 4.0^{* *} \\ 13.5 & 12.8\end{array}$

$\begin{array}{rr}5.8 & 2.4^{* *} \\ 18.1 & 10.3^{* *}\end{array}$

(4)

$3209^{*}$
$8.6^{* *}$
$1.2^{* *}$
$11.4^{* *}$

Medical Assistance

1989

Non-PCAP PCAP

(5)

(6)

Non-PCAP

1991

(7)

(8)

$\begin{array}{rrrr}3204 & 3297^{* *} & 3195 & 3287^{* *} \\ 9.9 & 6.1^{* *} & 11.0 & 6.1^{* *} \\ 1.9 & 0.7^{* *} & 2.4 & 0.9^{* *} \\ 12.5 & 10.3^{*} & 13.5 & 9.5^{* *}\end{array}$

$\begin{array}{rr}8.3^{* *} & 7.7 \\ 3.7^{* *} & 3.9 \\ 5.7^{* *} & 9.2 \\ 49.5^{* *} & 32.4\end{array}$

$8.6^{* *}$
3.9
$3.7^{* *}$
$46.9^{*}$

7.6

3.5

$8.8^{* *}$

32.4

11.5

31.3

$3.7^{* *}$

$4.7^{* *}$

$50.1^{* *}$

$\begin{array}{rrlrc}7.9 & 19.2 & 12.1^{* *} & 26.6 & 21.7^{* *} \\ 39.8^{* *} & 31.1 & 38.2^{* *} & 29.3 & 27.8 \\ 34.7^{* *} & 9.8 & 12.1^{* *} & 8.9 & 8.9 \\ 11.6 & 14.1 & 18.0^{* *} & 17.5 & 13.3^{* *} \\ 4.1 & 22.1 & 16.3^{* *} & 11.4 & 25.2^{* *} \\ 66.0^{* *} & 31.6 & 30.4 & 41.8 & 20.4^{* *} \\ 79.2 & 52.9 & 59.6^{* *} & 51.7 & 52.1^{* *} \\ 20.3 & 18.9 & 20.8^{* *} & 17.9 & 14.6^{*} \\ 5.2^{*} & 13.3 & 16.3 & 12.7 & 13.2^{* *}\end{array}$

2.2

$0.3^{* *}$

3.9

$0.3^{* *}$

4.3

3.2

7.1

$2.8^{* *}$

Schooling/Socioeconomic

Less than high school

College or more

$\begin{array}{rc}44.2 & 52.8^{* *} \\ 1.5 & 1.0\end{array}$

42.6
1.8
48.3
1.2
35.3
4.1
$39.9^{* *}$
3.6
27.6
6.5

${ }^{+}$means based on known values only

${ }^{a}$ Cash Assistance refers to women who were eligible for Medicaid because they receive cash assistance through either AFDC, SSI, or Home Relief; Medical Assistance refers to women who were not receiving cash assistance but who were enrolled in Medicaid through the Medical Assistance Program. PCAP indicates that the woman was enrolled in the Prenatal Care Assistance Program at some point during her pregnancy.

$\mathrm{b} * * \mathrm{P}<.01 ;{ }^{*} \mathrm{P}<.05$ based on pair-wise test by PCAP status. 
Adjusted Differences in Birth Weight (in grams) and Rates of Low Birth Weight, Very Low Birth Weight and Preterm Birth (in \% pts) Associated with Participation in the Prenatal Care Assistance Program

(PCAP) by Medicaid Status and Year of Delivery, New York City 1989 and $1991^{\text {a,b }}$

\section{PCAP specification}

Sample includes women with no prenatal care

Sample excludes women with no prenatal care

Term births only ( $>36 \mathrm{wks})$, excludes no care

\section{DEPENDENT VARIABLE: BIRTH WEIGHT (in grams)}

Cash Assistance
1989

$69^{*}$

$47^{*}$

$31^{+}$

1991

Medical Assistance 1989

1991

\section{DEPENDENT VARIABLE: LOW BW RATE (in \% pts)}

Cash Assistance
1989

Medical Assistance
1989

Sample includes women with $-2.3^{*}$

$-5.7^{*}$

$-3.9^{*}$

no prenatal care

Term births only ( $>36 \mathrm{wks}$ ), excludes no care

$-0.1$

$-1.8^{+}$

(0.6)

$(0.8)$

(0.6)

$-1.5^{\#}$

DEPENDENT VARIABLE: VERY LOW BW RATE (in \% pts)

\section{Cash Assistance} 1989

$-0.5$

$(0.3)$

$-0.4$

(0.3)
1991

$-1.1^{*}$

$-0.4$

$(0.3)$
Medical Assistance 1989 1991

$-1.6^{\circ}$

$-1.6^{*}$

(.50)

$-0.4$

$(0.3)$

no prenatal care

(1)

\footnotetext{
$b$ p $<.01 ;+\mathrm{p}<.05 ; \# \mathrm{p}<.10$
}

${ }^{a}$ For birth weight, figures represent differences in grams; for low birth weight, very low birth weight, and preterm birth figures reflect average treatment effects in percentage points. Standard errors are in parentheses. We estimate birth weight regressions by ordinary least squares and all dichotomous outcomes by probit. Regressions include controls for maternal age, race/ethnicity, nativity, previous fetal loss, maternal schooling, paternal schooling, marital status, sex of the infant and census tract poverty rates. 
Table 3

Adjusted Differences in Birth Weight (in grams) Associated with Participation in the Prenatal Care Assistance Program (PCAP) based on Comparisons of Women Who Initiate Care at the Same Point during Pregnancy by Medicaid Status and Year of Delivery, New York City 1989 and $1991^{a, b}$

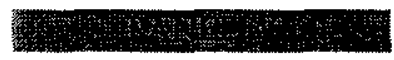

Prenatal care began.

Months 1-4

Months 5-6

Months $7+$

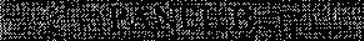

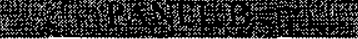

Prenatal care began..

Months 1-4

Months 5-6

Months $7+$

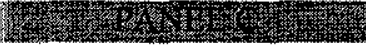

Prenatal care began.

Months 1-4

Months 5-6

Months $7+$

\begin{tabular}{cc}
\multicolumn{2}{c}{ Cash Assistance } \\
$\mathbf{1 9 8 9}$ & $\mathbf{1 9 9 1}$ \\
$\mathrm{n}=5181$ & $\mathrm{n}=5597$ \\
PCAP - nonPCAP & PCAP - nonP \\
& \\
& \\
$54^{+}$ & $82^{*}$ \\
$(21.6)$ & $(22.2)$ \\
26 & 69 \\
$(35.9)$ & $(37.9)$ \\
$74^{+}$ & 72 \\
$(35.8)$ & $(34.5)$
\end{tabular}

BASIC SPECIFICATION
Medical Assistance

1989

$\mathrm{n}=3713 \quad \mathrm{n}=5993$

PCAP - nonPCAP PCAP - nonPCAP
40

(24.6)

$-27$

(42.7)

$93^{\circ}$

(46.4) (33.8)

TOBACCO, COCAINE, OTHER HLICIT DRUGS INCLUDED

Cash Assistance

1989

1991

Medical Assistance

PCAP - nonPCAP PCAP - nonPCAP PCAP - nonPCAP PCAP - nonPCAP

1991 1989

\begin{tabular}{lcccc} 
& 1989 & 1991 & \multicolumn{2}{c}{1989} \\
& $\mathrm{n}=4519$ & $\mathrm{n}=4929$ & 1991 \\
& PCAP - nonPCAP & PCAP - nonPCAP & PCAP - nonPCAP & PCAP - nonPCAP \\
Prenatal care began.. & & & & \\
& & & & \\
Months 1-4 & $46^{+}$ & 36 & 33 & -3 \\
& $(19.7)$ & $(21.1)$ & $(21.8)$ & $(19.2)$ \\
Months 5-6 & -2 & 13 & $99^{+}$ & -34 \\
& $(28.6$ & $(33.9)$ & $(31.6)$ & $(34.5)$ \\
Months 7+ & 20 & 11 & 42 & 22 \\
& $(32.4)$ & $(31.1)$ & $(41.8)$ & $(29.8)$
\end{tabular}

${ }^{2}$ Figures in panel A show the birth weight difference in grams for infants born to women enrolled in PCAP versus infants born to women not in PCAP both of whom began prenatal care at approximately the same point of pregnancy adjusted for maternal age, race/ethnicity, nativity, previous fetal loss, maternal schooling, paternal schooling, marital status, sex of the infant, census tract poverty rates and health district of residence. Figures in Panel B add indicators of prenatal exposure to tobacco, cocaine and other illicit drugs to the specification in Panel A. Figures in Panel C are from the specification in Panel A excluding all preterm births.

${ }^{\mathrm{b}}$ Standard errors in parentheses. \# $\mathrm{p}<.10{ }^{+} \mathrm{p}<.05 ;{ }^{*} \mathrm{p}<.01$ 
Average Treatment Effects in Percentage Points on Low Birth Weight, Term Low Birth Weight and Very Low Birth Weight Associated with Participation in the Prenatal Care Assistance Program (PCAP) based on Comparisons of Women Who Initiate Care at the Same Point during Pregnancy by Medicaid Status and Year of Delivery, New York City 1989 and $1991^{\text {a,b }}$

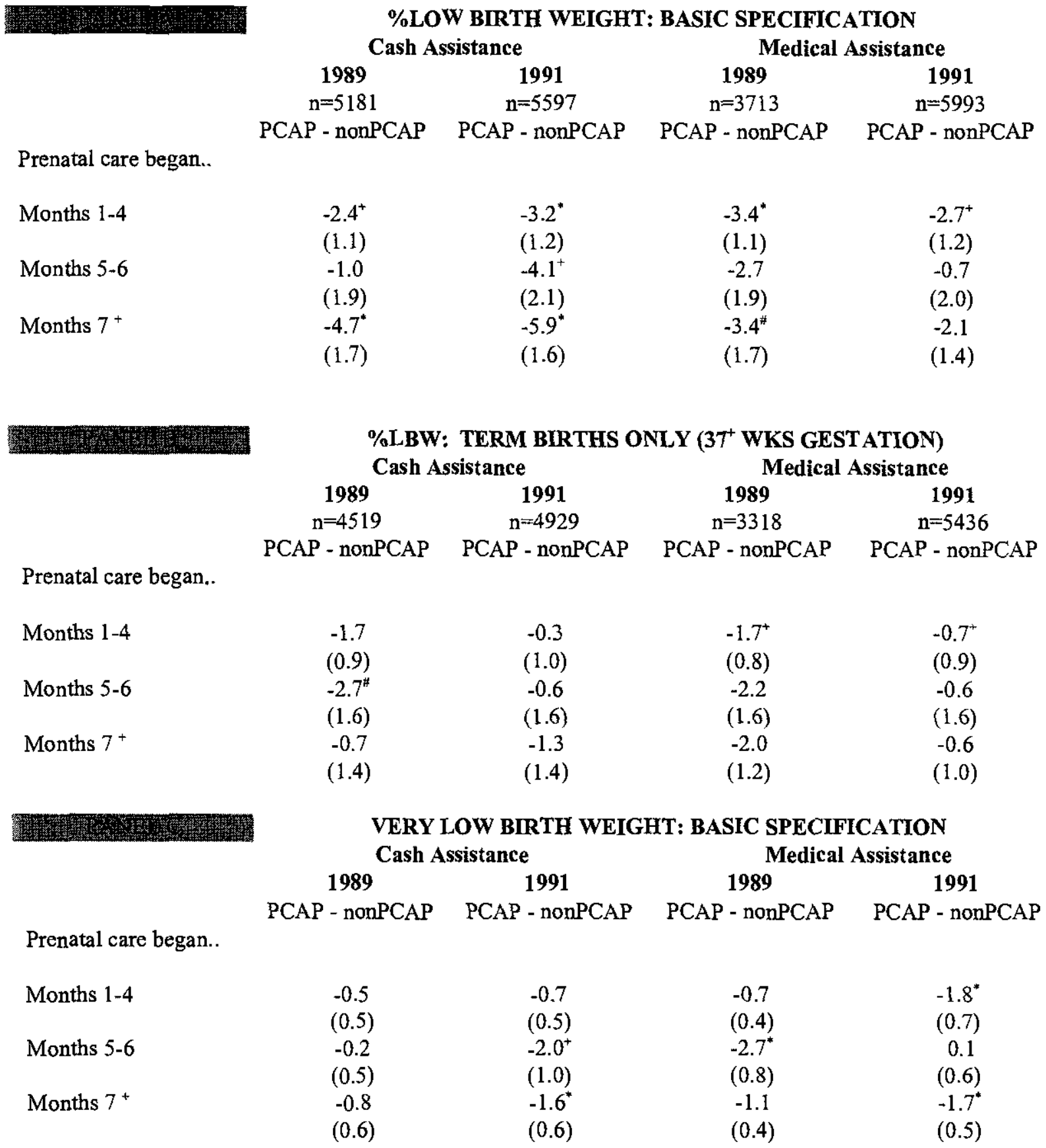

a. Figures in panel A show average treatment effects in percentage points for infants born to women enrolled in PCAP versus infants born to women not in PCAP both of whom began prenatal care at approximately the same point during pregnancy as estimated by probits. Models include controls for maternal age, race/ethnicity, nativity, previous fetal loss, maternal schooling, paternal schooling, marital status, local area poverty, sex of infant and health district of residence. Panel B displays average treatment effects for term births only and Panel $\mathrm{C}$ is for very low birth weight births.

${ }^{\mathrm{b}}$ Standard errors are in parentheses. ${ }^{\#} \mathrm{p}<.10 ;{ }^{+} \mathrm{p}<.05 ;{ }^{*} \mathrm{p}<.01$ 
Table 5

Average Treatment Effects in Percentage Points of WIC Enrollment and Adjusted Mean Differences Prenatal Care Visits Associated with Participation in the Prenatal Care Assistance Progarm (PCAP) by Medicaid Status and Year of Delivery, New York City 1989 and 1991,b

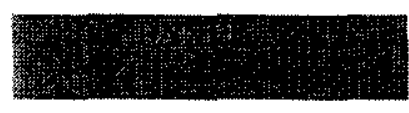

\section{DEPENDENT VARIABLE: WIC PARTICIPATION (\% pts)}

\begin{tabular}{cccc}
\multicolumn{2}{c}{ Cash Assistance } & \multicolumn{2}{c}{ Medical Assistance } \\
1989 & 1991 & 1989 & 1991 \\
$\mathrm{n}=5043$ & $\mathrm{n}=5468$ & $\mathrm{n}=3645$ & $\mathrm{n}=5889$ \\
PCAP - nonPCAP & PCAP - 110nPCAP & PCAP - nonPCAP & PCAP - nonPCAP \\
& & & \\
$8.2^{*}$ & $10.5^{*}$ & $9.4^{*}$ & $14.0^{*}$ \\
$(1.4)$ & $(1.5)$ & $(1.5)$ & $(1.3)$ \\
& & & \\
$7.3^{*}$ & $6.6^{+}$ & $7.7^{*}$ & $17.7^{*}$ \\
$(2.4)$ & $(2.8)$ & $(2.1)$ & $(2.4)$
\end{tabular}

DEPENDENT VARIABLE: PRENATAL CARE VISITS

(PCAP Interacted with Timing of First Visit: Terms Births Only)

All births with some care

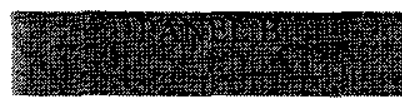

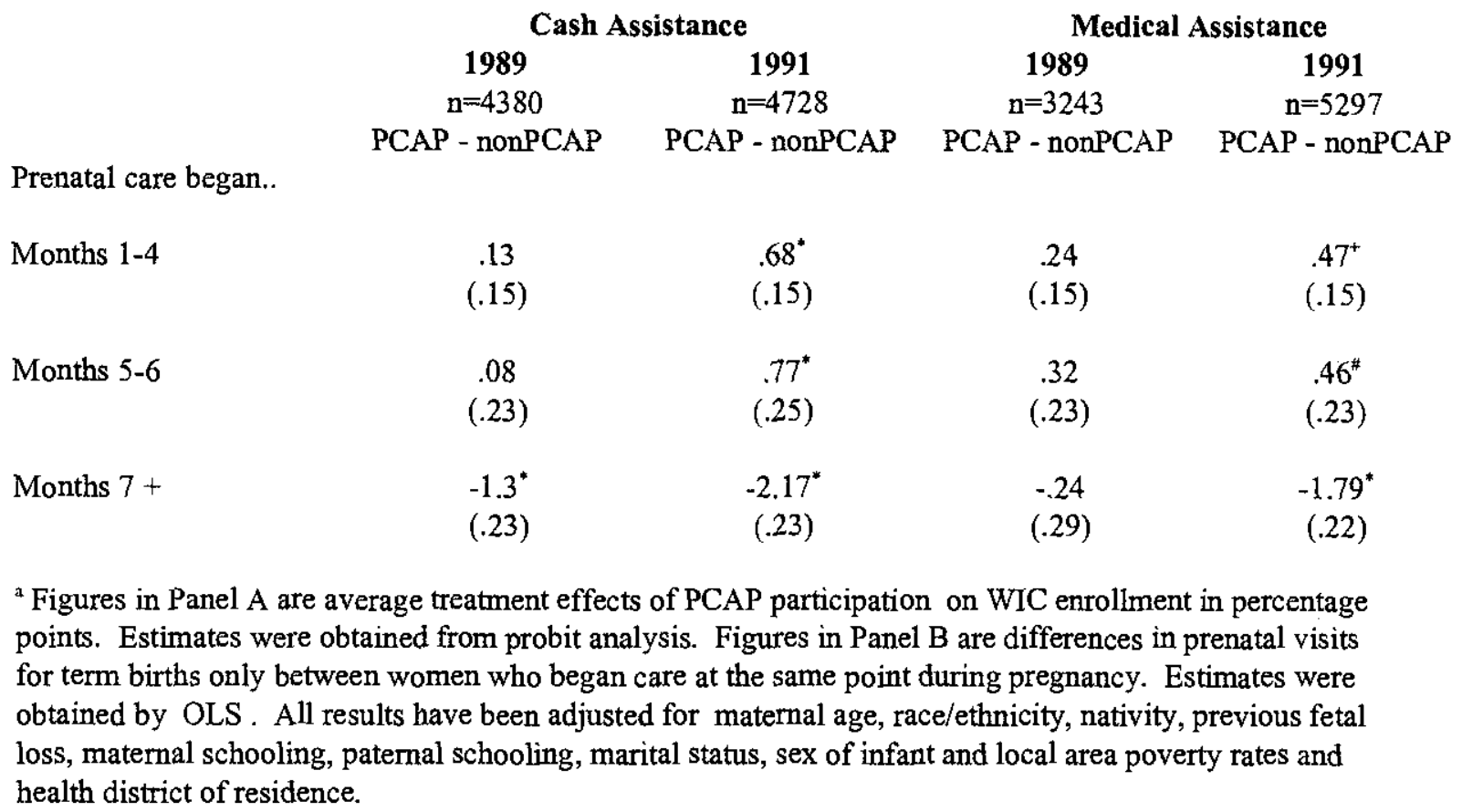

Prenatal care began..

${ }^{\mathrm{b}}$ Standard errors are in parentheses. \# $\mathrm{p}<.10 ;+\mathrm{p}<.05 ;{ }^{*} \mathrm{p}<.01$ 


\section{Table 6}

Differences in Birth Weight (in grams) and Rates of Low Birth Weight (in \% pts) Associated with Participation in the Prenatal Care Assistance Program (PCAP) as Estimated by Ordinary Least Squares (OLS), Probit, and Instrumental Variables (IV) by Medicaid Status in New York City, Pooled 1989 and $1991^{a, b}$

\section{DEPENDENT VARIABLE: BIRTH WEIGHT (in grams)}

\begin{tabular}{ccc}
\multicolumn{2}{c}{ Cash Assistance } & Me \\
OLS & IV & OLS \\
& & \\
$62^{*}$ & 88 & $43^{*}$ \\
$(11.8)$ & $(82.7)$ & $(12.0)$ \\
& & \\
0.2 & & -2.3 \\
41.0 & & 33.0 \\
$8.1^{*}$ & & $12.9^{*}$
\end{tabular}

Medical Assistance

OLS IV

$43^{*}$

$-38$

$\operatorname{PCAP}(\text { yes }=1)^{\mathrm{c}} \quad 62^{*}$

Hausman test (t-statistic)

Over-id test $\left(\chi_{30}\right)^{d}$

$F_{(30, \infty)}$ excluded instruments

DEPENDENT VARIABLE: LBW RATE (in \% pts)

Cash Assistance
Probit $\quad$ 2-Step-IV

$-2.5^{*}$

10778
10778

\section{Medical Assistance \\ Probit 2-Step-IV}

$-2.4^{*}$

9706
$-0.7$

9706

${ }^{a}$ Figures for birth weight are the coefficients on the indicator variable for PCAP participation. For low birth weight, figures represent average treatment effects or marginal effects in the two-step procedure in percentage points. Regressions include controls for maternal age, race/ethnicity, nativity, previous fetal loss, maternal schooling, paternal schooling, marital status, sex of the infant and census tract poverty rates, year and health district of residence. Birth weight regressions are estimated by two-stage least squares. I use Murphy and Topel's two-step estimator when low birth weight is the outcome.

${ }^{b}$ Standard errors are in parentheses.

$c * \mathrm{p}<.01 ;+\mathrm{p}<.05 ; \# \mathrm{p}<, 10$

${ }^{d}$ Critical value for $\chi_{30}$ at the .05 level is 43.8 at $p<.05$ and $F_{(30, \infty)}$ is 1.47 . 


\section{Table 7}

Changes in PCAP Participation, Birth Weight, Rate of Low Birth Weight, WIC Participation, and Prenatal Visits by Hospital of Delivery, Year and Medicaid Category, New York City, 1989-1991 ${ }^{\text {a }}$

\section{CASH ASSISTANCE}

\begin{tabular}{lrrrrrr} 
& $\begin{array}{c}\text { Never a PCAP } \\
\text { Hospital }\end{array}$ & \multicolumn{2}{c}{$\begin{array}{c}\text { Always a PCAP } \\
\text { Hospital }\end{array}$} & \multicolumn{2}{c}{$\begin{array}{c}\text { Changed to a PCAP } \\
\text { Hosiptal }\end{array}$} \\
& 1989 & 1991 & 1989 & 1991 & 1989 & 1991 \\
& & & & & & 149 \\
\# of births & 757 & 761 & 3120 & 3117 & 1040 & 1423 \\
\% in PCAP & 31.3 & $19.5^{*}$ & 80.5 & $84.2^{*}$ & 37.4 & $86.5^{*}$ \\
Mean birth weight & 3207 & 3202 & 3183 & 3183 & 3239 & 3248 \\
\% low BW & 8.6 & 10.4 & 10.1 & 9.3 & 7.4 & $7.9^{*}$ \\
\# prenatal visits & 8.6 & 8.6 & 8.2 & $8.5^{*}$ & 8.4 & $9.3^{*}$ \\
\% WIC & 36.7 & 39.7 & 43.1 & $40.8^{*}$ & 55.5 & $65.1^{*}$
\end{tabular}

\section{MEDICAL ASSISTANCE}

\section{Never a PCAP \\ Hospital}

1989

352

22.4

3261

7.1

8.6

38.1

1991

\section{Always a PCAP \\ Hospital}

1989

2243

58.1

3270

6.9

8.6

42.0

1991

3037
$91.0^{*}$
$3297^{\#}$
6.0
$9.0^{*}$

$44.9^{+}$
Changed to a PCAP Hosiptal

1989

1991

1028

2187

$25.8 \quad 87.6^{*}$

$3289 \quad 3272$

7.4

8.9

39.8

$a * p<.01 ;+p<.05 ; \# p<.10$ 
Table 8

Reduction in 1991 Newborn Costs Associated with Participation in the Prenatal Care Assistance Program, New York City 1989 and 1991

\section{Change in Newborn Costs Associated with a Reduction in Birth Weight of ....}

$\begin{array}{cccc}\begin{array}{c}\text { Evaluated } \\ \text { at... }\end{array} & \mathbf{3 0} \text { grams } & \mathbf{5 0} \text { grams } & \mathbf{7 0} \text { grams } \\ \$ 2,165^{\mathrm{a}} & -\$ 189 & -\$ 305 & \\ \$ 3,696^{\mathrm{b}} & -\$ 323 & -\$ 521 & -\$ 414 \\ & & \end{array}$

Change in Newborn Costs Associated with a Reduction in the Rate of Low Birth Weight of ....

Evaluated
$1.0 \%$ pts
$2.0 \%$ pts
$3.0 \%$ pts

at..

$\$ 2,165$

$-\$ 61$

$-\$ 122$

$-\$ 183$

$\$ 3,696$

$-\$ 104$

$-\$ 208$

$-\$ 313$

a The geometric mean of newborn costs for infants of women on Medicaid who delivered in a New York City public hospital in $1991(\mathrm{n}=22,285)$.

${ }^{b}$ Predicted cost (in 1991 dollars) for a male infant who weighs 2500 grams assuming mother is U.S.- born, Black, non-Hispanic, between 21 and 34 years of age, unmarried, with less than a high school education and with father's education unknown based on newborn costs regressions. See Appendix Tables 2 and 3 for regressions estimates. 
Marginal Effects and Standard Errors (in parentheses) from First-stage Regression of PCAP Participation Estimated by Ordinary Least Squares and Maximum Likelihood Probit by Medicaid Status for Pooled Years 1989 and $1991^{\mathrm{a}}$

DEPENDENT VARIABLE: PCAP Participation (1=yes)

Cash Assistance

Mother's Age

Age 20-34

Age $<20$

Age $>34$

Male infant $($ yes $=1)$

Parity

Second or higher birth

First birth

Parity unknown

Previous fetal loss (yes $=1$ )

Unmarried (yes $=1$ )

\section{Race/Ethnicity}

White/other

Black non-Hispanic

Puerto Rican

Dominican

Other Hispanic

Race/ethnicity unknown

Nativity

Foreign born

Born in US

Birth place unknown
OLS

. .01

(.01)

$-.02$

(.02)

$-.01$

(.01)

Probit
Medical Assistance

OLS 
Mother's Schooling

Less than high school

High school

$-.02^{+}$

(.01)

Some college

$-.05^{*}$

(.01)

Schooling unknown

.02

(.03)

$-.02$

(.02)

$-.05$

(.04)

.02

(.03)

$-.02^{*}$

(.01)

$-.03^{+}$

(.01)

$-.02$

(.02)

$-.02^{+}$

(.01)

$-.03^{+}$

(.01)

Father's Schooling

$-.02$

(.02)

Less than high school

High school

$-.03$

(.01)

Some college

$-.002^{\#}$

(.02)

Schooling unknown

$-.02$

(.01)

$\%$ poor in census tract

$.001^{*}$

$(.000)$

$-.04$

(.03)

$-.003$

(.02)

$-.02$

(.02)

.001

(.001)

-na-

.05

(.05)

.02

(.01)

-na-

.09

(.09)

.02

(.02)

$-.02^{*}$

(.01)

$-.03$

(.02)

$-.02^{*}$

(.01)

$.001^{*}$

$(.000)$

$.05^{+}$

(.02)

$.47^{*}$

(.07)

$.05^{+}$

(.02)

$-.03$

(.01)

$-.03$

$(.02)$

$-.03$

(.01)

$.001^{*}$

$(.000)$

.05

(.02)

$.45^{*}$

(.07)

.04

(.02)

$\mathrm{R}^{2}$ or Puesdo $\mathrm{R}^{2}$

.11

.09

.23

.20

$F_{(29, \infty)}$ or $\chi^{2}{ }_{(29,)}$ for health districts ${ }^{b}$

$19.5^{*}$

$436^{*}$

$15.1^{*}$

$288^{*}$

$F_{(29, \infty)}$ or $\chi_{(29,)}^{2}$ for health districts $\mathrm{x} y \mathrm{yr}$

$8.2^{*}$

$202^{*}$

$12.9^{*}$

$280^{*}$

$\mathrm{N}$

10,778

10,778

9,706

9,706

${ }^{\mathrm{*}} \mathrm{p}<.01 ;{ }^{+} \mathrm{p}<.05 ;{ }^{*} \mathrm{p}<.10$

${ }^{b}$ Critical value for $\mathrm{F}_{(29, \infty)}$ is 1.47 and $\chi_{(29,)}^{2}$ is 42.56 . 
Appendix Table 2

New York City Hospitals by PCAP Status 1989-1991

\section{Hospitals that changed from a non-PCAP provider to a PCAP provider between 1989- 1991}

Long Island College
Elmhurst"
New York Hospital
Beth Israel
NY Downtown (Beekman)
Bellevue*
Metropolitan*
Interfaith
Brooklyn
Maimonides
Methodist
Flushing
Jamaica

\section{Hospitals that were always PCAP providers between 1989-1991}

Harlem*

St John's Episcopal

Albert Einstein

Lutheran

Lincoln"

Union

St Vincent's

St Lukes/ Roosevelt

North Central ${ }^{*}$

Bronx Lebanon

Coney Island*

Kings*

Montefiore

Our Lady of Mercy

St Mary's

Bronx Municipal*

Mount Sinai

Queens Hospital Center*

Staten Island Hos

Woodhull

\section{Hospitals that were never PCAP Providers between 1989-1991}

Booth Memorial

Lennox Hill

Columbia Presbyterian ${ }^{b}$

New York University

Long Island Jewish

LaGuardia Hospital

St. John's Queens

\footnotetext{
${ }^{\text {a }}$ This list has been constructed from memos from the New York State Department of Health, Office of Perinatal Health Unit to PCAP providers as well as from provider lists based on claim records from PCAP providers to the New York State Department of Social Services, Division of Health and Long Term Care. I eliminated a branch of Saint John's Episcopal hospital, the Interfaith Medical Center, because I could not determine from any lists whether the Interfaith Center served PCAP recipients in 1989.

* Indicates that the facility is a municipal hospital

${ }^{b}$ Includes the Allen Pavilion and Sloane Hospital for Women
} 


\section{Appendix Table 3}

Coefficients from Regression of the Natural Logarithm of Newborn Costs on Birth Weight and Birth Weight Squared Adjusted for Demographic and Socio-economic Charateristics of the Mother from Linked Discharge Abstracts and Birth Certificates in the Now York City Public Hospitals, 1991

Variable
Constant
Age<20
Age>34
Other Hispanic
Puerto Rican
Dominican
Black non-Hispanic
Racelethnicity unknown
Born in US
Birth Place Unknown
First Birth
Parity Unknown
Previous fetal loss (yes=1)
Male infant (yes=1)
Unmarried (yes=1)
Mother high school
Mother some college
Mother education unknown
Father high school
Father some college
Father education unknown
Weight
Weight squared
R-squared
N

Parameter Standard T for HO: Estimate Error Parameter $=0$

\begin{tabular}{rrr}
13.02 & 0.05 & 246.77 \\
-0.12 & 0.01 & -10.11 \\
0.03 & 0.01 & 2.48 \\
-0.01 & 0.01 & -0.66 \\
0.10 & 0.01 & 7.61 \\
0.10 & 0.01 & 7.45 \\
0.05 & 0.01 & 4.45 \\
0.01 & 0.02 & 0.46 \\
0.12 & 0.01 & 12.61 \\
-0.04 & 0.07 & -0.62 \\
-0.06 & 0.01 & -6.56 \\
-0.01 & 0.02 & -0.23 \\
0.04 & 0.04 & 1.14 \\
0.04 & 0.01 & 5.27 \\
0.06 & 0.01 & 6.04 \\
-0.08 & 0.01 & -8.81 \\
-0.07 & 0.01 & -5.45 \\
0.01 & 0.03 & 0.53 \\
-0.05 & 0.01 & -4.22 \\
-0.03 & 0.02 & -1.88 \\
-0.01 & 0.01 & -1.02 \\
0.003 & 0.00 & -91.36 \\
\hline $41 \times 10^{\hat{o}}$ & 0.00 & 74.76
\end{tabular}




\section{Appendix Table 4}

\section{Coefflcients from Regression of the Natural Logarithm of Newborn Costs on Low Birth Weight Adjusted for Demographic and Socio-economic Charateristics of the Mother from Linked Discharge Abstracts and Birth Certificates in the New York City \\ Public Hospitals, 1991}

Variable
Constant
Age $<20$
Age $>34$
Other Hispanic
Puerto Rican
Dominican
Black non-Hispanic
Racelethnicity unknown
Born in US
Birth Place Unknown
First Birth
Parity Unknown
Previous fetal loss (yes=1)
Male infant (yes=1)
Unmarried (yes=1)
Mother high school
Mother some college
Mother education unknown
Father high school
Father some college
Father education unknown
Low birth weight
R-squared
N

\begin{tabular}{crr}
$\begin{array}{c}\text { Parameter } \\
\text { Estimate }\end{array}$ & Etandard T for HO: \\
7.47 & 0.01 & \multicolumn{1}{l}{ Parameter 0} \\
-0.12 & 0.01 & -9.98 \\
0.03 & 0.01 & 1.97 \\
-0.01 & 0.01 & -0.75 \\
0.11 & 0.01 & 7.85 \\
0.10 & 0.01 & 6.60 \\
0.07 & 0.01 & 5.45 \\
0.03 & 0.03 & 1.09 \\
0.13 & 0.01 & 12.85 \\
-0.03 & 0.07 & -0.40 \\
-0.04 & 0.01 & -4.77 \\
-0.01 & 0.02 & -0.45 \\
0.10 & 0.04 & 2.62 \\
0.03 & 0.01 & 4.34 \\
0.05 & 0.01 & 5.09 \\
-0.08 & 0.01 & -8.99 \\
-0.07 & 0.01 & -5.34 \\
0.05 & 0.03 & 1.85 \\
-0.05 & 0.01 & -4.49 \\
-0.03 & 0.02 & -1.56 \\
0.00 & 0.01 & 0.40 \\
1.34 & 0.01 & 102.58 \\
& & \\
0.361 & & \\
22284 & &
\end{tabular}

